\title{
AÇOS HIPEREUTETÓIDES PARA FABRICAÇÃO DE ROLAMENTOS AUTOMOTIVOS: ESTUDO E CARACTERIZAÇÃo DO AÇO SAE 52100
}

\author{
Anderson Elias Furtado ${ }^{1}$, Denise Ferreira Laurito Nascimento ${ }^{1}$, Paulo Ricardo Silva \\ Theodoro ${ }^{1}$ e Wesley da Silva Teodoro ${ }^{1}$ \\ ${ }^{1}$ FARO - Faculdade de Roseira. Engenharia Mecânica \\ E-mails: anderson.furtado@faroroseira.edu.br, denise.laurito@faroroseira.edu.br, \\ paulotheodoro1989@icloud.com,wesley.teodoro@gerdau.com.br
}

\section{RESUMO}

$\mathrm{Na}$ antiguidade observou-se que mover um objeto com o mínimo esforço requeria o uso de trilhas de cilindros, geralmente de madeira, utilizadas para arrastar o objeto ao invés do simples deslizamento do mesmo ao longo superfície. No século XV, Da Vinci desenvolvera mancais de rolamento em madeira e bronze.

Atualmente, o setor automobilístico é o responsável pela maior parte da utilização dos rolamentos. Os aços mais utilizados na fabricação de rolamentos são os SAE 52100, cujo elevado teor de carbono e cromo confere importantes propriedades mecânicas e apresenta excelente resposta a tratamentos térmicos. A fabricação dos aços para rolamentos ocorre em algumas etapas: ajuste da composição, solidificação, laminação, esferoidização e produção das bobinas.

Neste trabalho foram analisadas as propriedades mecânicas e microestruturais em diferentes etapas de produção do aço SAE 52100. As análises foram realizadas em três etapas: nas barras após ajuste da composição (conforme retirado da aciaria), após esferoidização e no produto acabado (rolamento temperado). Para cada condição foram realizadas análises químicas, metalográficas, ensaios de tração e microdureza. Assim, caracterizou-se o material e a adequação do mesmo ao processo, considerando todas as etapas de produção até o produto final.

\section{INTRODUÇÃO}

Os rolamentos são componentes cuja função é minimizar a fricção entre as peças móveis de um determinado equipamento, permitindo a rotação de uma parte em contato com a outra. $\mathrm{Na}$ antiguidade, as principais aplicações foram observadas em carroças e posteriormente em rodas de bicicleta. Após o período da Revolução Industrial a utilização dos rolamentos foi aperfeiçoada, através do desenvolvimento de aços com melhores características e processos de fabricação mais eficientes.

Diferentes tipos de aços podem ser obtidos a partir da adição de elementos liga no ferro. Os principais elementos presentes no aço são o $\mathrm{Cr}, \mathrm{Mn}, \mathrm{Si}, \mathrm{Mo}, \mathrm{V}, \mathrm{Nb}, \mathrm{W}, \mathrm{Ti}, \mathrm{Ni}$, além de outros elementos em quantidades residuais como por exemplo o $\mathrm{P}, \mathrm{S}$ e o $\mathrm{Si}$ oriundos do processo de fabricação. A adição desses elementos modifica as faixas de temperatura em que ocorrem as transformações alotrópicas, podendo estabilizar uma ou outra estrutura, além de formar novos constituintes importantes no aço, gerando uma enorme gama de ligas para diversos tipos de aplicação [1]. Atualmente os rolamentos são fabricados a partir de uma enorme gama de aços, 
selecionados de acordo com o processo de fabricação, condição de aplicação, dimensão e tipo de tratamento térmico empregado.

Os rolamentos mesmo em condições normais de operação, são expostos a diversos efeitos do meio nos quais podem se destacar as vibrações, impacto, desalinhamento, partículas de impurezas, etc. Devido a esses efeitos, o material no qual os rolamentos são fabricados devem apresentar elevada resistência mecânica, dureza, resistência superficial e considerável tenacidade [2].

Os rolamentos podem ser produzidos a partir de aços de baixo, médio e alto teor de carbono. Em aços de alto carbono os principais tratamentos térmicos responsáveis pelo aumento de resistência mecânica são a têmpera e o revenimento. Dentre os diversos tipos de aço de elevado carbono, o que apresenta maior predominância no mercado mundial para a fabricação de rolamentos é o SAE 52100. O aço SAE 52100, objeto de estudo deste trabalho, trata-se de um aço de baixa liga e elevado carbono, com teores de cromo variando de 1,0 a 1,5\%.

Esse artigo foi dividido nos seguintes capítulos: revisão da literatura, onde foram discutidos os rolamentos, processos de fabricação dos aços para os rolamentos e as propriedades necessárias em cada etapa desse processo; Metodologia utilizada para a caracterização do material; Resultados e análises. Conclusões.

\section{ROLAMENTOS}

Os rolamentos são constituídos a partir de três componentes principais: os anéis com pistas, os corpos rolantes e um elemento retentor dos corpos rolantes. A pista é a superfície onde os corpos rolantes giram, sendo composta por um anel externo e outro interno. A carga aplicada no rolamento é suportada por esta superfície de contato. Geralmente o anel interno se fixa no eixo e o externo no mancal [3].

Os corpos rolantes são classificados em dois tipos: esferas e rolos. As esferas apresentam um contato pontual com as pistas dos anéis interno e externo, enquanto a superfície de contato dos rolos é linear. Teoricamente, os rolamentos são construídos para permitir que os corpos rolantes girem orbitalmente enquanto giram em seu próprio eixo ao mesmo tempo. As gaiolas são classificadas como o elemento retentor, que servem para separar os corpos rolantes em intervalos regulares entre as pistas internas e externas permitindo que girem livremente [3]. Neste trabalho, será abordada a caracterização do aço utilizado na fabricação das pistas.

Os rolamentos são classificados em dois principais grupos: os rolamentos de esferas e os rolamentos de rolos. Adicionalmente os rolamentos podem também ser classificados de acordo com a direção em que é aplicada a carga, ou seja, rolamentos radiais suportam cargas radiais e rolamentos axiais suportam cargas axiais [4]. Na Figura 1, a seguir, pode-se visualizar rolamentos de rolo e de esferas, em representações esquemáticas, a fim de se permitir a identificação de suas partes constituintes. 


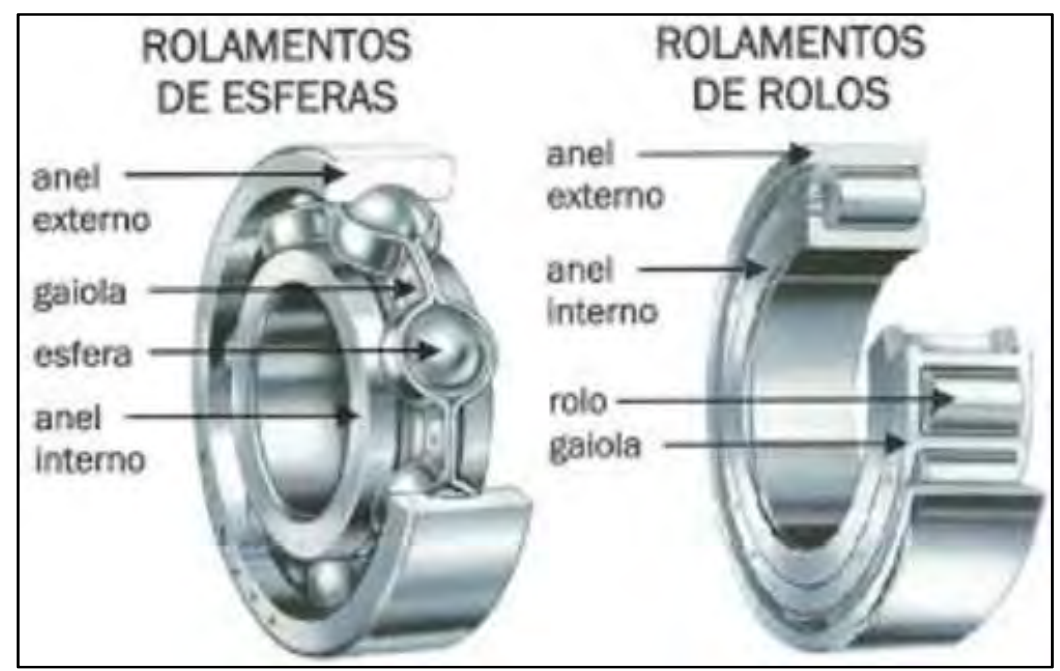

Figura 1. Representação esquemática de rolamentos de esferas e de rolos. Fonte: [4]

\section{AÇOS E A FABRICAÇÃO DE ROLAMENTOS}

A produção de aço pode ser considerada um forte indicador do desenvolvimento econômico de um país. Seu consumo cresce proporcionalmente à construção de edifícios, execução de obras públicas, instalação de meios de comunicação e produção de equipamentos. Esses materiais já se tornaram corriqueiros no cotidiano, mas fabricá-los exige técnica que deve ser renovada de forma cíclica, por isso o investimento constante das siderúrgicas em pesquisa [5].

Se a análise for focada ao Brasil, o setor siderúrgico é composto por 14 empresas privadas, controladas por nove grupos empresariais, operando 28 usinas distribuídas por 10 estados brasileiros. A evolução no consumo de aço está relacionada a vários fatores, nos quais podem se destacar o aumento da renda, a evolução do PIB e do produto industrial. Os setores de construção civil, automotivo, de bens de capital, utilidades domésticas, comerciais, embalagens e recipientes são responsáveis por consumir $80 \%$ da produção nacional, sendo o setor de construção civil responsável por 30\% desse montante [6].

Os aços utilizados na produção de rolamentos, além de apresentar uma microestrutura adequada a partir da composição química e tratamento térmico, devem também apresentar um baixíssimo nível de inclusões metálicas, sendo este um requisito fundamental para a durabilidade dos rolamentos [7]. As inclusões metálicas atuam como facilitadores de nucleação de trincas e por isso devem ser mantidas em níveis baixíssimos para que não ocorram falhas precoces do componente em serviço [8].

Em aços de alto carbono, o recozimento é o primeiro tratamento a ser utilizado com o objetivo de se obter uma microestrutura esferoidizada. Este tratamento induz a modificação da perlita lamelar para carbonetos esferoidizados em matriz ferrítica, proporcionando a diminuição da dureza, aumento da conformabilidade e ductilidade do material, além de ser considerada uma excelente microestrutura anterior à têmpera, implicando em uma menor tendência ao crescimento do grão austenítico, menor tendência ao fissuramento, maior intervalo admissível de temperaturas, além de proporcionar maior resistência e tenacidade ao aço [9], [10].

Outro tratamento importante em aços para rolamento é a têmpera, a partir da formação de uma microestrutura metaestável decorrente de resfriamento acelerado com transformação da fase 
austenítica em martensita. Na produção de rolamentos em escala industrial, o tratamento térmico de têmpera seguido de revenimento é amplamente utilizado logo após uma etapa de conformação mecânica dos componentes, como estampagem ou pós usinagem.

Os rolamentos podem ser produzidos a partir de aços de baixo, médio e alto teor de carbono. Ambas as classes de aço vêm sendo amplamente utilizadas dependendo das características particulares de processamento e aplicação. Por exemplo, os aços com elevados teores de carbono são mais apropriados para condições de aplicação com alta tensão de contato, como os rolamentos de esfera, e apresentam maior estabilidade dimensional em maiores variações de temperatura, em função de uma menor quantidade de austenita retida [2].

Por outro lado, os rolamentos cementados apresentam uma maior ductilidade superficial, em função do maior volume de austenita retida, aumentando a resistência dos efeitos concentradores de tensão devido a irregularidades na superfície e presença de partículas de impurezas. Nos processos usuais de cementação, o teor de carbono na superfície do aço chega a valores na ordem de $1 \%$, aumentando a temperabilidade nessas regiões, e permitindo assim na sua posterior têmpera a formação da fase martensítica. Essa transformação de fase na superfície (austenita para martensita) gera um aumento expressivo da dureza nessas regiões, e consequentemente um aumento da resistência ao desgaste do aço. É interessante observar que mesmo com dureza superficial elevada, ele mantém o núcleo do material (ainda de baixo carbono) relativamente tenaz. Além disso, as tensões de compressão na superfície do material, resultantes deste tratamento, fazem com que sua resistência à fadiga seja bastante elevada [11].

Os aços médios carbono podem ser representados pelos aços SAE 1053, que apresentam cerca de $0,53 \%$ carbono. Os aços de baixo carbono podem ser representados pelas séries em que os teores de carbono variem em torno de 0,20\%, nos quais destacam-se os aços 8620, 5120, 4120 . Esses aços são cementados para que a camada superficial tenha resistência e o núcleo tenha deformabilidade e tenacidade. A microestrutura dos aços de baixo carbono é composta de martensita de alto carbono, com austenita retida na faixa de 15 a $40 \%$, e dureza superficial em torno de 58 a 64 HRC [12].

Dentre os diversos tipos de aço de elevado carbono, o que apresenta maior predominância no mercado mundial para a fabricação de rolamentos é o SAE 52100. O aço SAE 52100 normalmente é fornecido na condição laminada a quente, com uma microestrutura perlítica incluindo a presença de cementita proeutetóide, oriunda dos contornos de grão da austenita. Em experimentos realizados por Bhadeshia [13], pode-se notar que a cementita proeutetóide, quando formada nos contornos de grão da austenita, demonstrou afetar negativamente a vida em fadiga de rolamentos em testes conduzidos a tensões superiores a 5GPa. Segundo Gembalova e colaboradores [14], algumas medidas podem ser tomadas a fim de minimizar a formação da cementita proeutetóide, como por exemplo, um aquecimento suficientemente rápido a partir da temperatura final de deformação ou por recozimento para esferoidizar a cementita. A microestrutura de um aço SAE 52100 pode ser observada na Figura 2. Em (a) a microestrutura após o processo de laminação e em (b), a microestrutura após a esferoidização. 


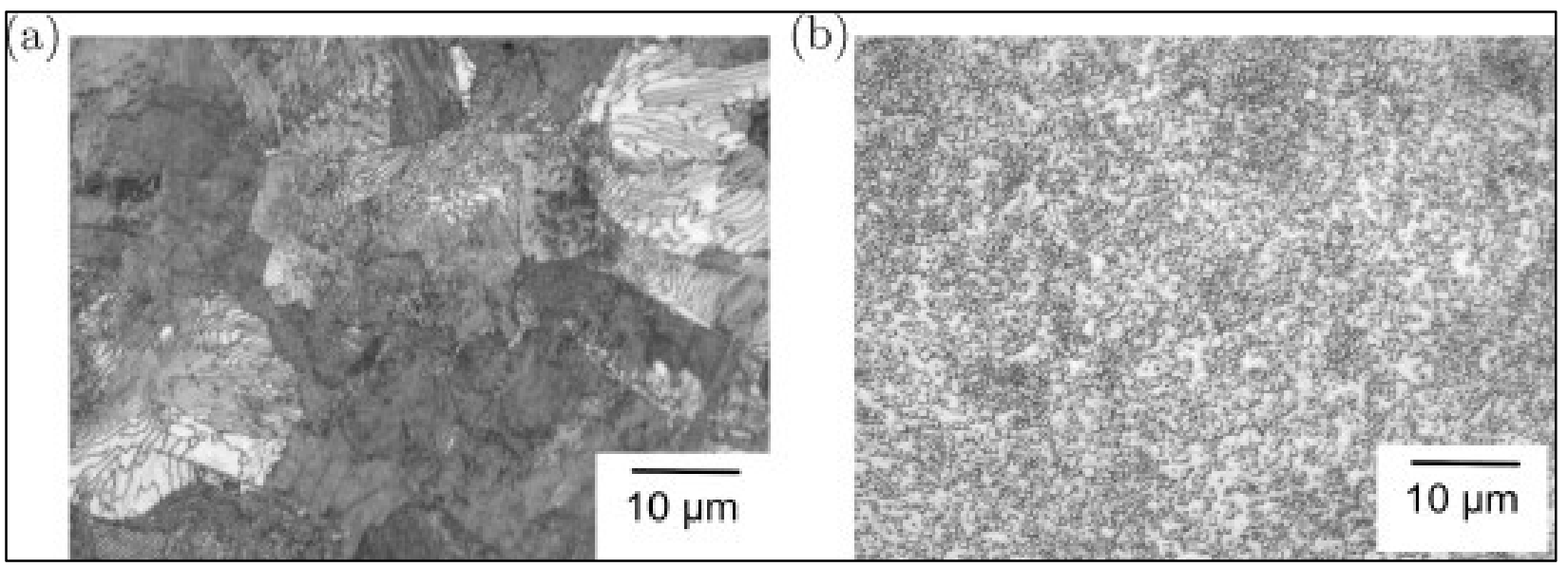

Figura 2. Microestrutura aço SAE 52100 antes e após processo de esferoidização. Fonte [13].

Os aços SAE 52100 são facilmente temperáveis (óleo ou sal) e na sequência revenidos. Após esses tratamentos sua microestrutura típica passa a ser de matriz martensítica, com carbonetos primários (não dissolvidos durante austenitização) e austenita retida entre 5 e 15\%. A dureza ao longo da seção de um aço rolamento temperado é normalmente de 60 a 64 HRC [14].

\section{MÉTODOS DE CARACTERIZAÇÃO DO MATERIAL}

As amostras utilizadas neste trabalho foram extraídas de três diferentes etapas do processo de produção do aço SAE 52100, fornecido pela empresa Gerdau para Faculdade de Roseira FARO. O material base utilizado neste projeto pode ser definido como um aço de alto carbono com adição de pequenas quantidades de elementos de ligas, conforme apresentado na Tabela 1.

Tabela 1 - Tabela de composição química aço SAE 52100.

\begin{tabular}{|c|c|c|c|c|c|c|c|c|c|}
\hline \multirow{2}{*}{ Material } & \multicolumn{9}{|c|}{ Elementos } \\
\cline { 2 - 9 } & $\mathbf{C}$ & Mn & Si & Cr & Ni & Mo & Cu & Sn & P \\
\hline SAE 52100 & $0,98-1,03$ & $0,38-0,41$ & $0,16-0,32$ & $1,39-1,43$ & 0,07 & 0,02 & 0,12 & $0,017-0,06$ & $0,019-0,12$ \\
& & & & & & & & & \\
\hline
\end{tabular}

Adaptado de [15]

Os corpos de provas para as análises desse estudo foram retirados em 3 etapas do processo de fabricação, conforme indicado abaixo, e podem ser vizualizados na Figura 3, a seguir:

- Condição 1: Amostra retirada após acerto da composição química no processo de refino secundário (Aciaria);

- Condição 2: Amostra retirada do material após processo de tratamento térmico de esferoidização (Laminação);

- Condição 3: Amostra retirada do material acabado no cliente, após processo de tratamento térmico tempera total (SKF); 


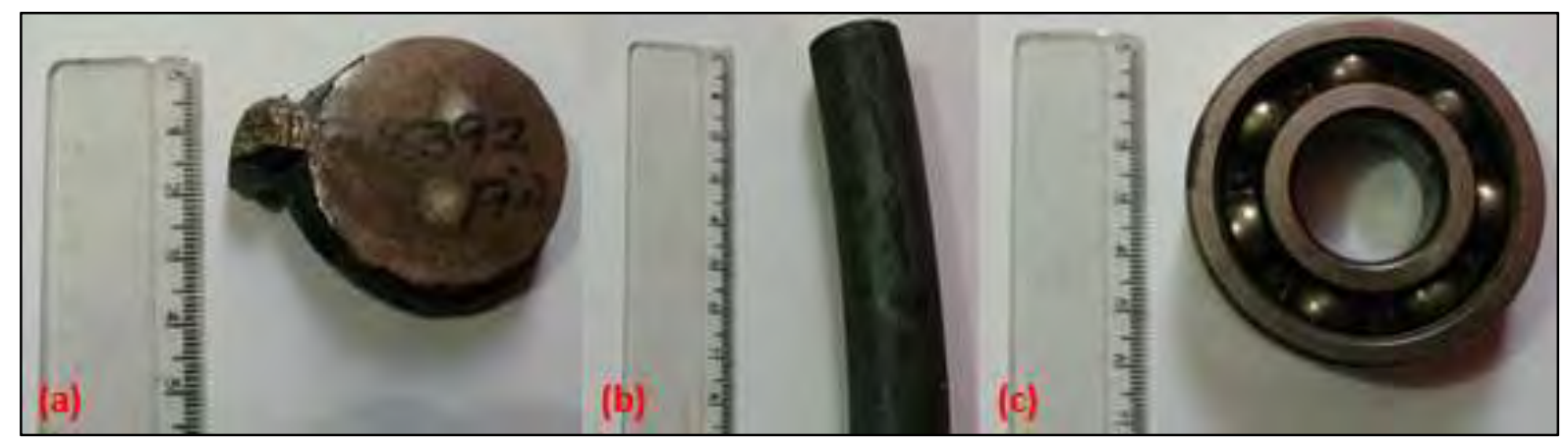

Figura 3. Representação das amostras utilizadas para elaboração deste projeto. Em (a) material na condição 1 , em (b), material na condição 2 e em (c) material na condição 3 .

Fonte: [autores]

A fim de caracterizar o material e confirmar que as características do mesmo em cada etapa do processo de fabricação são as mais adequadas, foram realizadas análises químicas, ensaios de tração, microscopia ótica e medições de microdureza Vickers ao fim das diferentes condições de processo. No Quadro 1, a seguir, podem ser observadas em que condições cada ensaio foi realizado.

Quadro 1. Condições nas quais cada caracterização foi ou não realizada nesse trabalho.

\begin{tabular}{|c|c|c|c|}
\hline Caracterização & Condição 1 & Condição 2 & Condição 3 \\
\hline \hline Análise Química & Realizada & Não & Não \\
\hline Ensaios de Tração & Realizados & Realizados & Não \\
\hline Microscopia Ótica & Realizada & Realizada & Realizada \\
\hline Microdureza Vickers & Realizada & Realizada & Realizada \\
\hline \multicolumn{4}{|c|}{ Fonte: [autores] }
\end{tabular}

Cabe ressaltar que as análises químicas foram realizadas em uma única etapa simplesmente pelo fato de não haver qualquer mudança de composição nas etapas subsequentes. Já os ensaios de tração, não puderam ser realizados na Condição 3 pelo fato de não ser geometricamente possível extrair um corpo-de-prova para o ensaio de tração do rolamento acabado.

\subsection{Análises Químicas}

A análise da composição química do material foi efetuada via espectrometria de emissão ótica, conforme a norma ASTM-A322-91. Ela foi realizada a partir de duas amostras circulares obtidas a partir da secção transversal, com dimensões de $40 \mathrm{~mm}$ de diâmetro por $10 \mathrm{~mm}$ de altura. Os principais elementos analisados foram: Carbono (C), Manganês (Mn), Enxofre (S), Silício (Si), Cromo (Cr) e o Molibdênio (Mo). 


\subsection{Ensaios de Tração}

Os testes de tração foram baseados na norma ASTM E8 e realizados em um equipamento com capacidade de $150 \mathrm{kN}$ e velocidade de $1 \mathrm{~mm} / \mathrm{min}$. Foram produzidos três corpos de prova, retirados da amostra na condição 1 e outros três da amostra na condição 2. Devido à dificuldade de obtenção de novos corpos de prova extraídos do rolamento acabado, não foi possível realizar esse ensaio no material na condição 3 .

\subsection{Análise Metalográfica}

Para a caracterização metalográfica foram produzidas três amostras de cada condição do processo. As amostras das condições 1 e 2 foram retiradas da secção transversal, apresentando uma seção quadrada de aproximadamente $25 \mathrm{~mm}^{2}$ de região útil. As amostras retiradas da condição 3 foram extraídas a partir da secção transversal com sua forma, apresentando, $5 \mathrm{~mm}$ de comprimento por $3 \mathrm{~mm}$ de largura. Todas foram submetidas a um embutimento à quente com baquelite e seguiram o procedimento padrão de preparação para microscopia ótica. $\mathrm{O}$ ataque químico foi realizado com $\mathrm{o}$ reagente Nital $2 \%$ (98\% de álcool etílico e $2 \%$ ácido nítrico), por 10 segundos.

As imagens apresentadas neste trabalho foram obtidas via microscopia óptica. As ampliações utilizadas neste equipamento foram de 50,100, 200, 500 e 1000 vezes, de forma aleatória em diversos pontos da sua superfície a fim de verificar a microestrutura do metal em toda a sua extensão.

\subsection{Microdureza Vickers}

As amostras utilizadas para o ensaio de microdureza do material foram as mesmas utilizadas para a análise metalográfica. As medidas de microdureza foram realizadas ao longo da seção transversal das amostras utilizando uma carga de $1 \mathrm{kgf}$, durante $30 \mathrm{~s}$, com base na norma ASTM E384-16.

\section{RESULTADOS E ANÁLISES}

\subsection{Composição Química}

Inicialmente, realizou-se uma análise da composição química do material na condição 1, a fim de verificar se o mesmo atendia às especificações obtidas na literatura, conforme observado de acordo com a Tabela 2. Essa composição química corresponde ao lote do qual foi produzido o componente ensaiado.

Tabela 2 - Composição Química da amostra analisada nesse projeto.

\begin{tabular}{|c|c|c|c|c|c|c|c|c|c|c|}
\hline \multirow{2}{*}{ Material } & \multicolumn{10}{|c|}{ Elementos } \\
\cline { 2 - 10 } & $\mathbf{C}$ & $\mathbf{M n}$ & $\mathbf{S i}$ & $\mathbf{P}$ & $\mathbf{C r}$ & $\mathbf{N i}$ & $\mathbf{M o}$ & $\mathbf{C u}$ & $\mathbf{A l}$ & Sn \\
\hline SAE 52100 & $1,02 \%$ & $0,49 \%$ & $0,27 \%$ & $0,08 \%$ & $1,41 \%$ & $0,06 \%$ & $0,02 \%$ & $0,05 \%$ & $0,02 \%$ & $0,05 \%$ \\
\hline
\end{tabular}

Fonte: [autores] 
Uma analogia entre a Tabela 2 (valor obtido) e a Tabela 1 (valor da literatura) permite concluir que o material do lote em questão estava dentro do especificado, tratando-se, portanto, de componentes quimicamente conformes, podendo ser definido o material como um aço SAE 52100.

De acordo com a Tabela 2, observa-se que o teor de carbono se encontra em aproximadamente 1\%. De acordo com Callister, aços que apresentam teores de carbono que variam na faixa de $0,77 \%$ e $2,11 \%$ são classificados como aços hipereutetóides, e apresentam uma microestrutura característica que será posteriormente discutida no item das análises metalográficas [16].

\subsection{Caracterização Microestrutural}

\subsubsection{Microscopia ótica na Condição 1: Como fornecido}

Na primeira etapa, de acordo com a Figura 4, verificou-se uma microestrutura bruta oriunda do processo de solidificação.

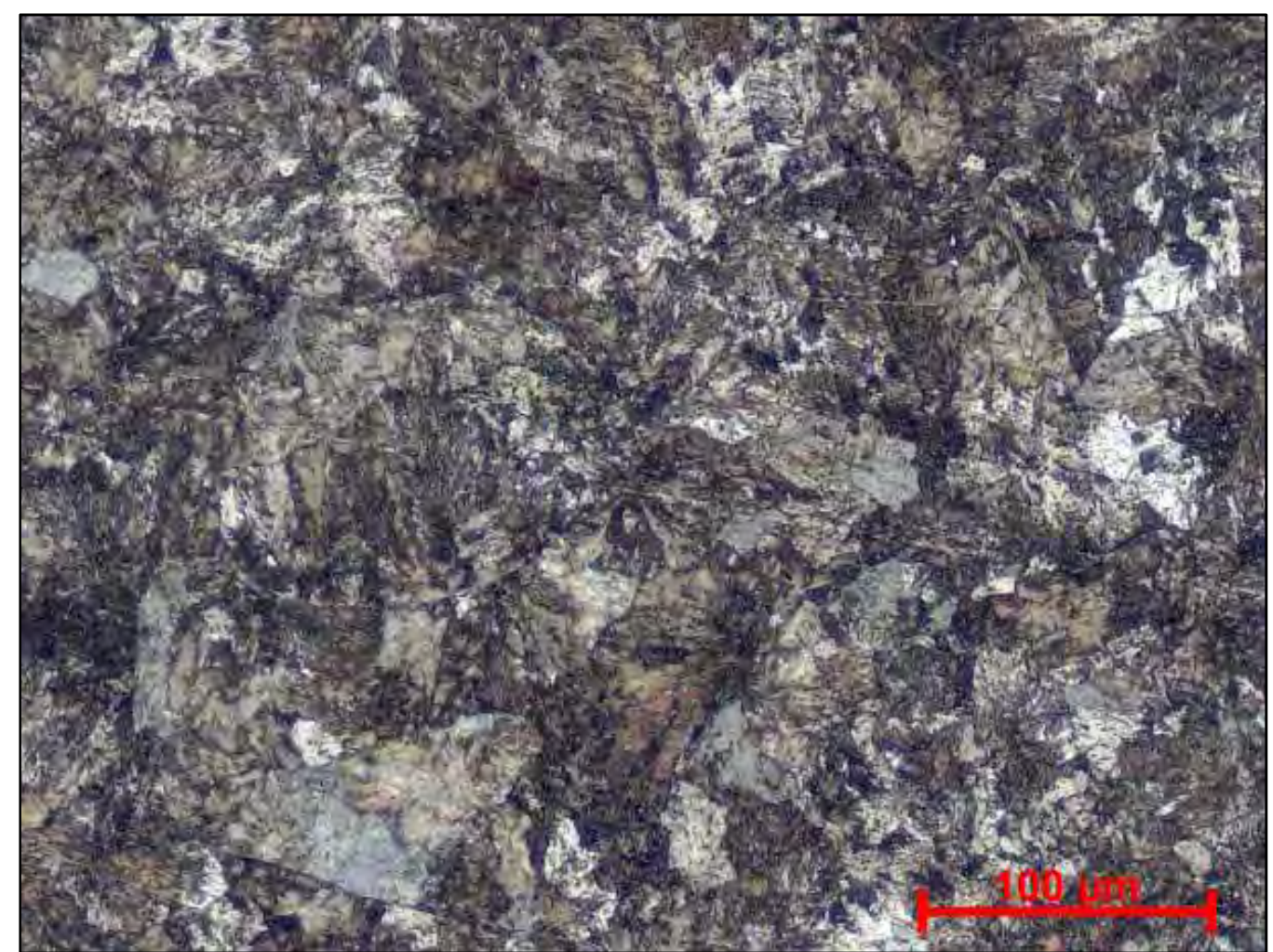

Figura 4. Microestrutura da região central do material na condição 1. A fase escura é composta de cementita pró-eutetóide e a fase clara da imagem por perlita. Nital 2\%. Aumento de 200x. Fonte: [autores].

Sendo assim, este material pode ser caracterizado como um aço hipereutetóide. Os aços com aproximadamente $1 \%$ de carbono, acima da linha eutetóide, apresentam uma microestrutura composta por austenita e cementita proeutetóide. Abaixo da linha eutetóide, a cementita passa a ser considerada como do tipo eutetóide e apresenta-se na forma de finas lamelas dispersa em uma matriz ferrítica, sendo então denominada de perlita [17]. 
Em experimentos realizados por Bhadesha, verificou-se no aço SAE 52100 uma microestrutura compatível com a observada neste projeto, sendo caracterizada como do tipo perlítica com cementita proeutetóide nos contornos de grão. Porém em ensaios acelerados de fadiga conduzidos pelo autor, em tensões superiores a $5 \mathrm{GPa}$, verificou-se a presença da cementita proeutetóide nos contornos de grão, afetando negativamente a vida em fadiga [13]. Uma das alternativas utilizadas para diminuir os efeitos da cementita proeutetóide, na vida em fadiga consistia em submeter o material ao tratamento de esferoidização, a fim de esferoidizar a cementita [18].

\subsubsection{Microscopia ótica na Condição 2: esferoidizado}

Na segunda etapa, de acordo com a Figura 5, verificou-se a formação de uma microestrutura globular composta por carbonetos esferoidizados em uma matriz ferrítica, oriunda do processo de tratamento térmico de esferoidização.

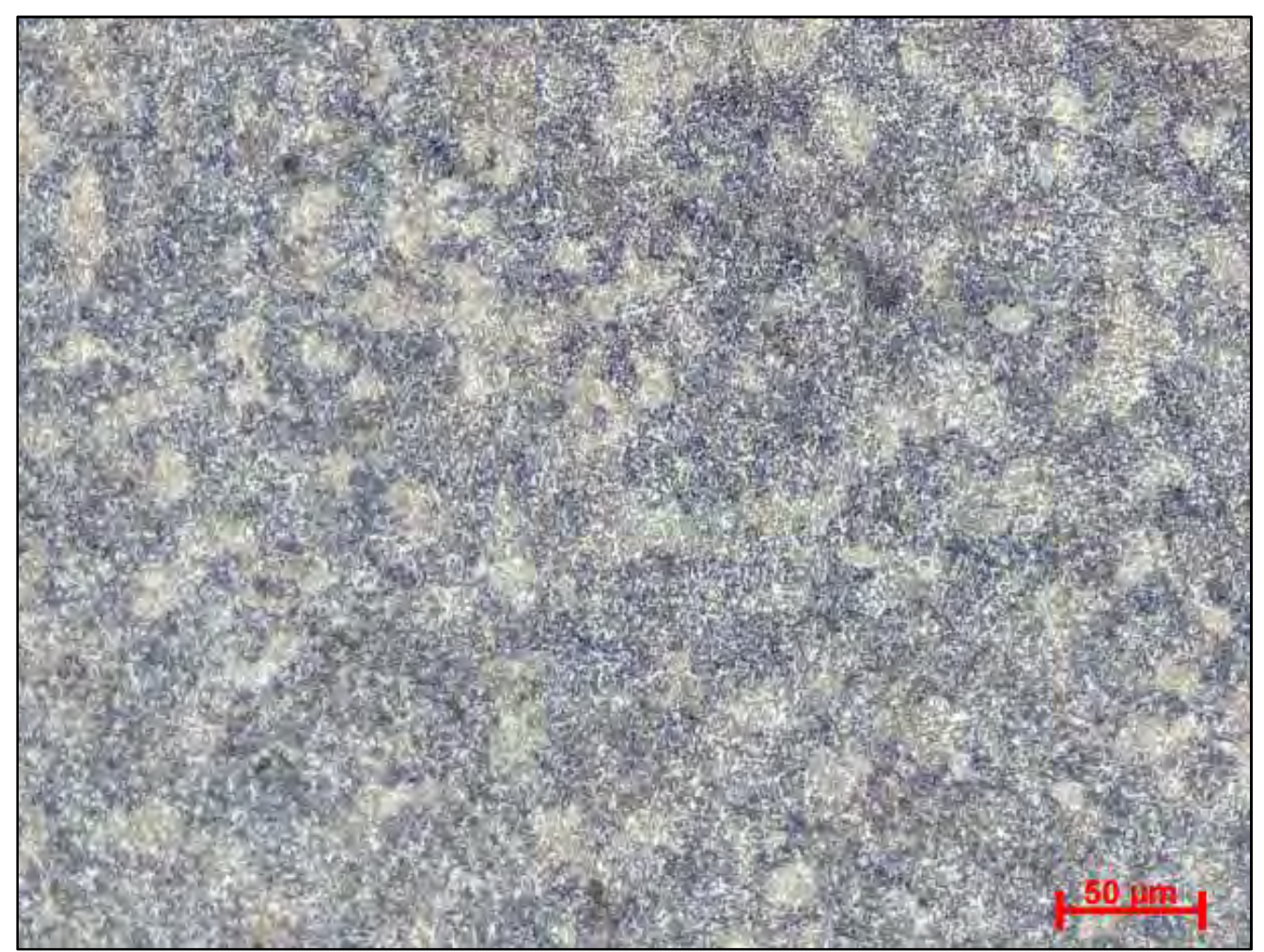

Figura 5. Microestrutura da região central do material na condição 2 . Nital 2\%. Aumento de 200x. Fonte: [autores].

A esferoidização pode ser considerada como um processo de ajuste morfológico, onde ocorre uma evolução microestrutural da perlita a partir de um mecanismo de coalescimento, com consequente formação de carbonetos globulares em uma matriz ferrítica, tendo efeito determinante nas propriedades dos aços de médio e alto carbono [19]. 
A terceira etapa, representada pela Figura 6, ilustra a microestrutura obtida do componente acabado. Como resultado do tratamento térmico de têmpera e revenimento empregado, as amostras sofreram uma transformação martensítica homogênea ao longo de suas espessuras. Assim, na Figura 6, observa-se a microestrutura constituída por martensita fina com carbonetos uniformemente distribuídos.

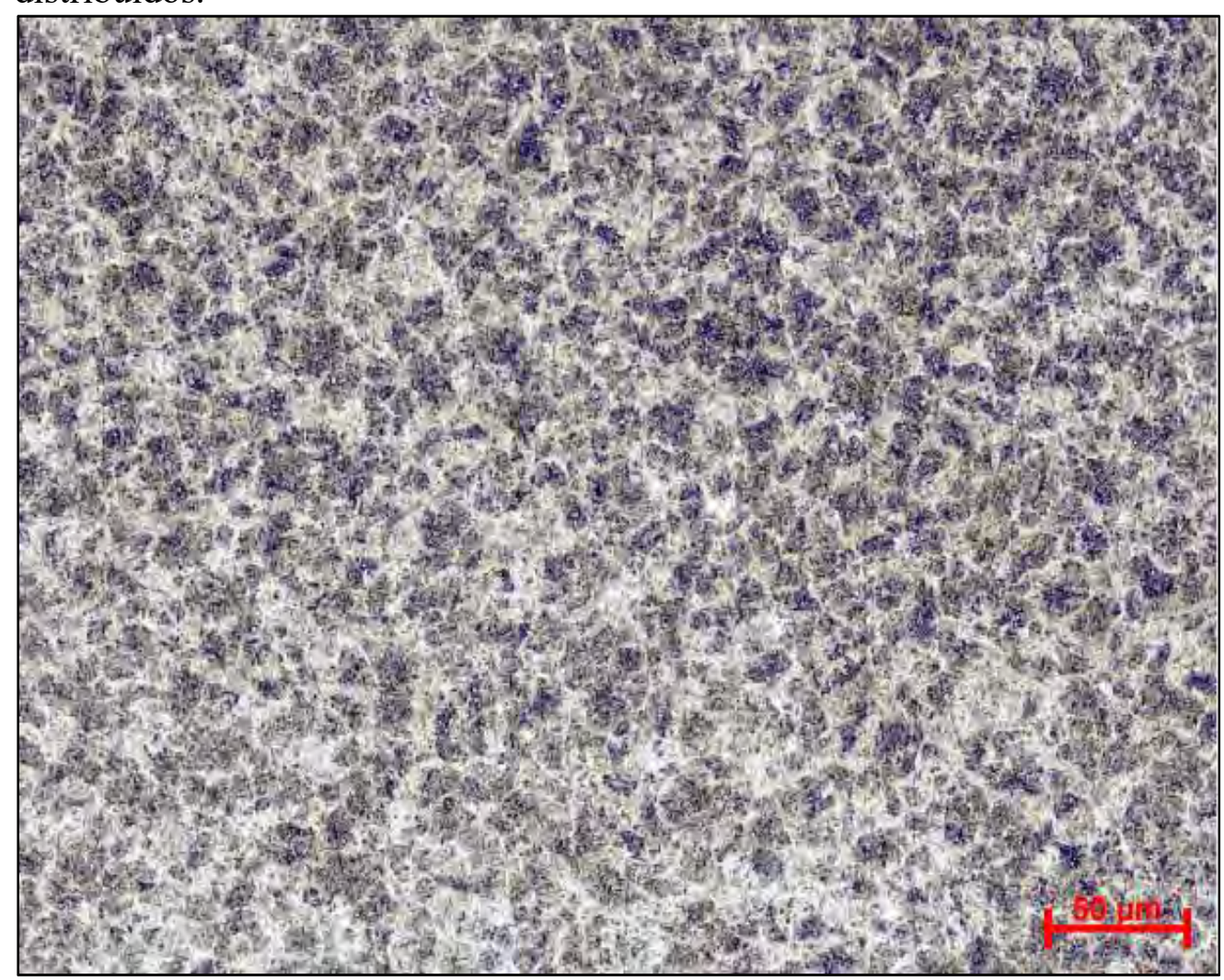

Figura 6. Microestrutura da região central do material na condição 3. Nital 2\%. Aumento de 200x. Fonte: [autores].

Os componentes para rolamentos que serão submetidos à têmpera total na fase de tratamento térmico foram fabricados a partir de aços com microestrutura esferoidizada. A microestrutura contendo inicialmente carbonetos homogeneamente distribuídos, provenientes do processo de esferoidização, após a têmpera terá uma microestrutura martensítica também homogênea, porém com carbonetos mais finos, devido à dissolução do carbono durante a austenitização, com valores de dureza na faixa de 600 a $900 \mathrm{HV}$ [20].

\subsection{Microdureza Vickers}

Os valores médios de microdureza para todas as condições podem ser observados de acordo com a Figura 7. Para a amostra na condição 1 a dureza foi de aproximadamente $209 \mathrm{HV}$ e desvio padrão de \pm 2 , para a condição 2 aproximadamente $237 \mathrm{HV}$ com desvio padrão de \pm 2 e para a condição 3 de $748 \mathrm{HV}$ com um desvio de \pm 17 . 


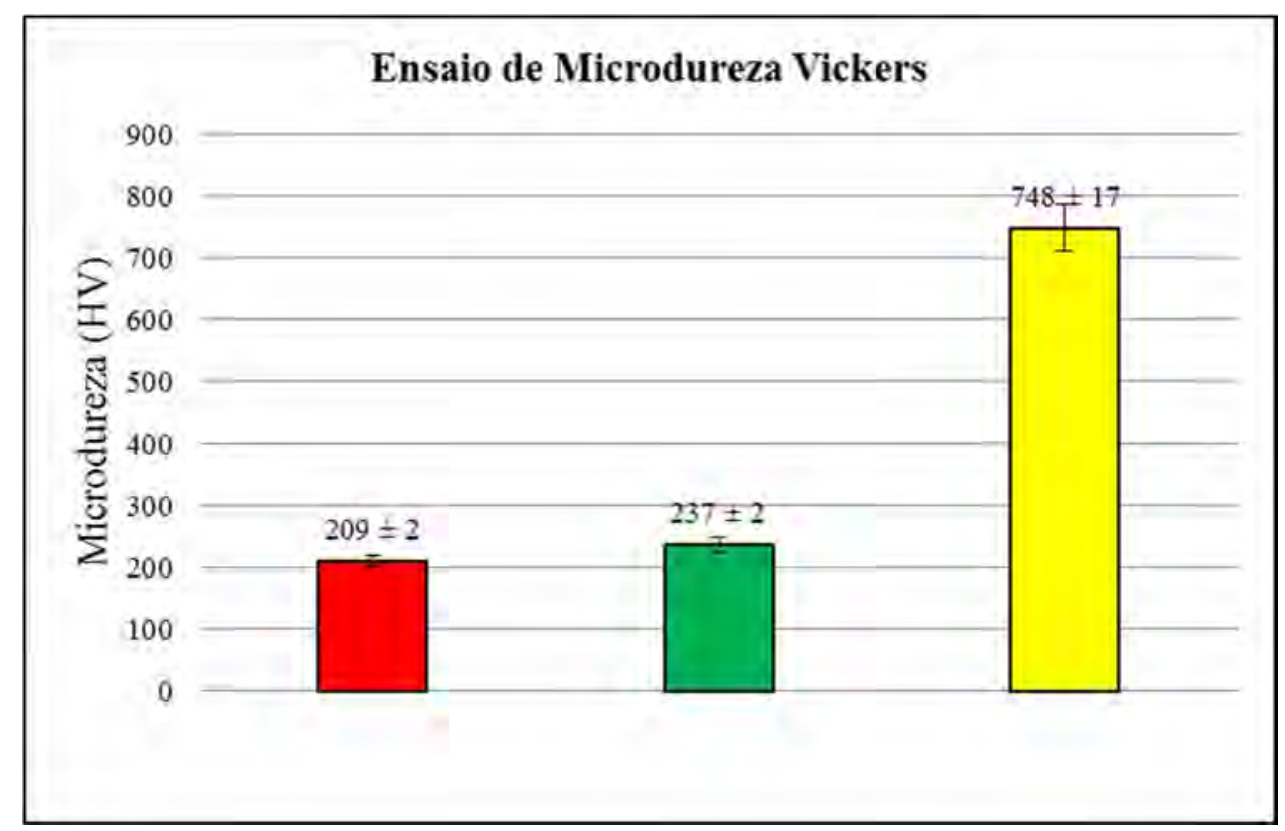

Figura 7. Valores médios de microdureza Vickers ensaiados com carga de $1 \mathrm{kgf}$.

Fonte: [autores]

De acordo com os valores médios pode-se notar um aumento percentual de aproximadamente $13 \%$ no valor da dureza da amostra na condição 2 e de $250 \%$ na condição 3 quando comparadas a etapa inicial.

As medidas de dureza dos materiais na condição 1 e 2 apresentaram-se com valores relativamente próximos, conforme observado na Figura 21. Após o processo de laminação, os valores médios de dureza, encontrados para um aço de elevado carbono ligado ao cromo foram de aproximadamente $297 \mathrm{HV}$ [21]. De acordo com os resultados obtidos na condição 2 , o valor médio de dureza encontrado neste trabalho foi de $237 \mathrm{HV}$, estando a aproximadamente $20 \%$ menor quando comparado ao valor encontrado por Oyama e colaboradores [21], indicando a eficiência do processo de esferoidização na redução do valor de dureza.

Em experimentos realizados por Bhadeshia, após o tratamento de tempera seguido de revenimento, pode-se observar que a faixa de dureza encontrada no produto acabado variava de $674 \mathrm{HV}$ a $865 \mathrm{HV}$, estando em bom acordo com os valores encontrados neste trabalho [13]. O elevado valor de dureza pode ser atribuído aos carbonetos secundários ou de transição, dispersos no interior dos cristais martensíticos, que substituem os átomos individuais de carbono como agentes controladores da resistência mecânica [22].

\subsection{ENSAIOS DE TRAÇÃO: RESISTÊNCIA MECÂNICA E DUCTILIDADE}

Os valores medidos nesse experimento para a Tensão de escoamento, o Limite de resistência à tração e o Alongamento do aço SAE 52100, para as condições 1 e 2, como fornecido e esferoidizado, respectivamente, foram agrupados na Tabela 3, a seguir. 
Tabela 3 - Resultados obtidos nos ensaios de tração do Aço SAE 52100.

\begin{tabular}{|c|c|c|c|c|c|c|}
\cline { 2 - 7 } & \multicolumn{2}{c|}{$\begin{array}{c}\text { Limite de escoamento } \\
\text { (Ge) }\end{array}$} & $\begin{array}{c}\text { Limite de Resistencia à Tração } \\
\text { (ORT) }\end{array}$ & \multicolumn{2}{c|}{$\begin{array}{c}\text { Alongamento } \\
\text { (A) }\end{array}$} \\
\cline { 2 - 7 } & $\begin{array}{c}\text { Média } \\
\text { (MPa) }\end{array}$ & $\begin{array}{c}\text { Desvio Padrão } \\
\text { (MPa) }\end{array}$ & $\begin{array}{c}\text { Média } \\
\text { (MPa) }\end{array}$ & $\begin{array}{c}\text { Desvio Padrão } \\
\text { (MPa) }\end{array}$ & $\begin{array}{c}\text { Média } \\
\text { (\%) }\end{array}$ & $\begin{array}{c}\text { Desvio Padrão } \\
\text { (\%) }\end{array}$ \\
\hline $\begin{array}{c}\text { Condição 1 } \\
\text { Como fornecido }\end{array}$ & 310 & 29 & 476 & 44 & 18 & 2 \\
\hline $\begin{array}{c}\text { Condição 2 } \\
\text { Esferoizidado }\end{array}$ & 425 & 16 & 653 & 7 & 25 & 1 \\
\hline
\end{tabular}

Fonte: [autores]

A fim de facilitar a comparação entre as propriedades em cada condição, na Figura 8 está representada a correlação entre a variável de resistência (Limite de Resistência à Tração) em função do alongamento percentual da amostra na condição 1 e condição 2 .

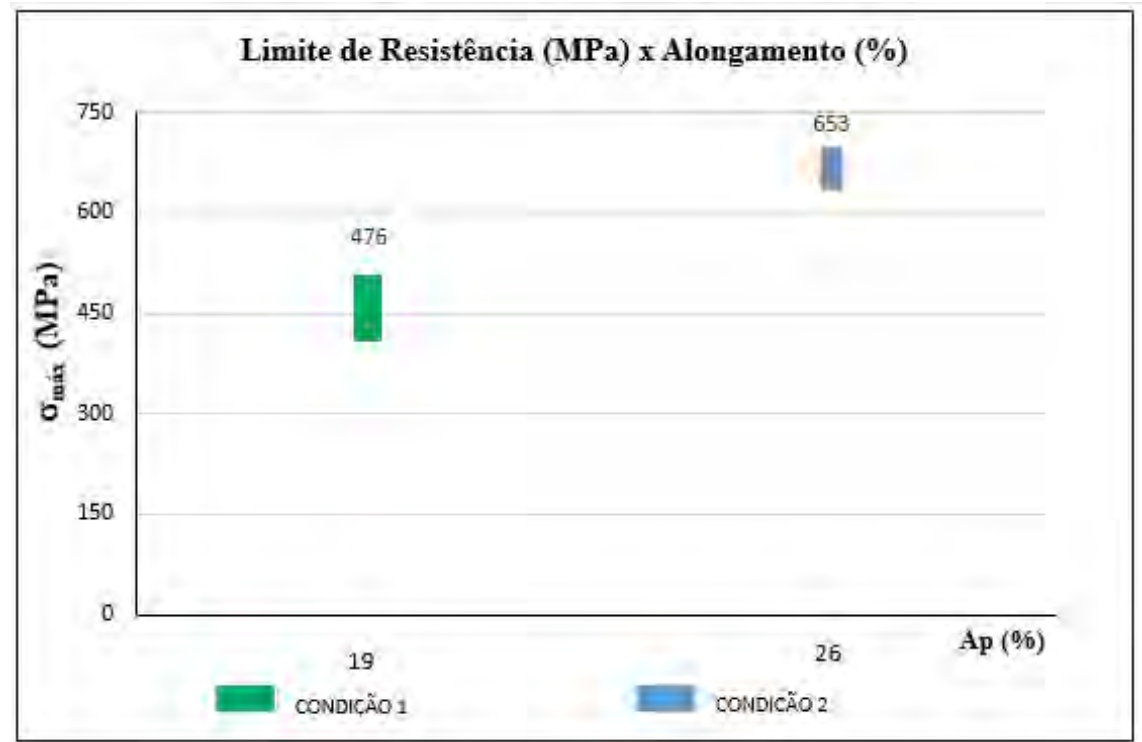

Figura 8. Correlação entre os valores de Resistência à tração e alongamento obtidos nos ensaios de tração do aço SAE 52100 nesse trabalho.

Fonte: [autores]

De acordo com os resultados anteriormente apresentados, pode-se verificar a influência do processo de tratamento térmico nas propriedades mecânicas do material, através do aumento de ambas as variáveis de resistência (limite de escoamento e limite de resistência à tração) e da variável de ductilidade (alongamento) da condição 2 quando comparada a condição 1 . O aumento do valor das variáveis de resistência pode ser atribuído à maior dureza superficial, conforme anteriormente verificado no item microdureza Vickers (4.3).

No aço SAE 52100, notou-se uma variação dos valores de resistência das amostras na condição 1 e na condição 2. Para a condição 1 os valores médios de resistência a tração, limite de escoamento, alongamento e redução de área foram de respectivamente de $1320 \mathrm{MPa}, 850 \mathrm{MPa}$ e 5,45 \%. Para a condição 2 os valores médios foram de $660 \mathrm{MPa}$, o limite de escoamento $440 \mathrm{MPa}$ e o alongamento $27 \%$. Os valores obtidos nesse projeto estão em acordo com aqueles obtidos por Silva [10]. 
O valor de resistência da amostra esferoidizada pode ser atribuído ao processo de laminação anterior ao processo de tratamento térmico. As deformações ocasionadas por esse processo mecânico, geram acúmulos de discordâncias, dificultando a deformação e aumentando a resistência mecânica a partir de um processo chamado de "encruamento" do material [23]. As tensões internas introduzidas pela deformação em conjunto com o elevado teor de carbono e cromo, atuam como um "facilitador" no processo de esferoidização, a partir da formação de carbonetos uniformemente dispersos na matriz, conferindo ao material um aumento de aproximadamente $20 \%$ no limite de resistência quando comparado ao material na condição 1 .

\section{CONCLUSÃO}

A análise química do material apresentou-se compatível com os valores obtidos na literatura. O teor de carbono encontrado foi de aproximadamente $1 \%$, o que permitiu classificar o aço como do tipo hipereutetóide.

Na condição inicial obtida após o ajuste da composição química, verificou-se a formação de uma estrutura bruta de solidificação composta de perlita (ferrita + cementita eutetóide) em regiões de coloração clara e de cementita pró-eutetóide, no contorno de grão, em regiões de coloração escura, característica de aços classificados como do tipo hipereutetóides.

Na condição esferoidizada, notou-se no material a formação de uma estrutura globular composta de carbonetos esferoidizados em uma matriz ferrítica. A formação dos carbonetos esferoidizados pode ser atribuída ao mecanismo de coalescimento da perlita em uma matriz ferrítica, tendo efeito determinante nas propriedades dos aços de médio e alto carbono.

Na condição temperada notou-se no material a formação de uma microestrutura constituída por martensita fina com carbonetos uniformemente distribuídos. Tal distribuição pode ser atribuída à estrutura inicial contendo carbonetos homogeneamente distribuídos após o processo de esferoidização.

O valor médio de microdureza para a condição inicial foi de aproximadamente $209 \mathrm{HV}$ e desvio padrão de \pm 2 . Para o material esferoidizado aproximadamente $237 \mathrm{HV}$ com desvio padrão de \pm 2 . E para o material temperado de $748 \mathrm{HV}$ com um desvio de \pm 17 . Notando-se um aumento percentual de aproximadamente $13 \%$ no valor da dureza da amostra esferoidizada e de $250 \%$ na amostra temperada quando comparadas à condição inicial.

A amostra na condição inicial apresentou valor médio de resistência a tração de aproximadamente $(476,55 \pm 44,92) \mathrm{MPa}$, limite de escoamento $(310,15 \pm 29,23) \mathrm{MPa}$ e alongamento de $(18,94 \pm 1,98) \%$. Para o material esferoidizado a resistência à tração foi de $(653,35 \pm 7,42) \mathrm{MPa}$, limite de escoamento $(425,15 \pm 16,47) \mathrm{MPa}$ e alongamento de $(25,97 \pm$ 1) $\%$.

Desta forma, a partir das análises das microestruturas encontradas e das propriedades mecânicas medidas nas diferentes etapas do processo de produção, comparando-as a dados da literatura, pode-se confirmar tratar-se de SAE 52100, utilizado na fabricação de rolamentos automotivos, em função de suas características de elevada resistência mecânica, resistência à corrosão e bom alongamento, entre outros. 


\section{REFERÊNCIAS}

[1] COLPAERT, Hubertus. "Metalografia dos produtos siderúrgicos comuns". 4. ed. São Paulo: Bluncher, 2008.

[2] ASM HANDBOOK. "Properties and Selection: Irons Steel and High Performance Alloys". v. 1, 2004.

[3] SKF GROUP. “General Catalogue”. Gothenburg, 2005.

[4] NTN. "Catalogo de Rolamentos". Disponível em

http://www.ntn.com.br/pdfServicos/indiceA13/indiceA13.pdf . Acesso em: fevereiro de 2017.

[5] INSTITUTO AÇO BRASIL. "O aço e o processo siderúrgico". Disponível em http://www.acobrasil.org.br/site/portugues/aco/processo--etapas.asp . Acesso em: março de 2017.

[6] AZENHA, Amanda Fortes. "Barreiras à entrada no setor siderúrgico brasileiro no período de 1993 a 2012". 127f. Trabalho de conclusão de curso - Faculdade de Ciências Agrárias e Veterinária do Campus de Jaboticabal, Universidade Estadual Paulista, Jaboticabal, 2013.

[7] MARTINS, Carlos Otávio Damas et al. "Comparação entre Técnicas de Análise de Tensões Residuais em Anéis de Rolamento do Aço ABNT 52100”. Revista Matéria, v. 09, n. 1, p. $20-28,2004$.

[8] BESWICK, John. "Effect of prior cold work on martensite transformation in SAE 52100". Metallurgical Transactions, 15A, p. 299 - 306, 1984.

[9] NOVIKOV, Ilia. "Teoria dos tratamentos térmicos dos metais". Editora UFRJ, Rio de Janeiro, 1994.

[10] SILVA, Wander Gomes; GOLDENSTEIN, Hélio. “Avaliação de propriedades mecânicas de um aço baixa liga alto carbono a partir da correlação entre ensaios mecânicos e metalúrgicos". 2005. 105 f. Dissertação (Mestrado em Engenharia Metalúrgica e Materiais) - EPUSP, São Paulo, 2005.

[11] WILLIAMS, G.T. "Selection of carburizing steel, case depth and heat treatment". Ohio: ASM, 1948. 681p.

[12] CAPPEL, Jürgem; WEINBERG, Matthias; FLENDER, Rheinhold. "The metallurgy of roller-bearing steels". Steel Grips, p. 261-268, 2004.

[13] BHADESHIA, Harshad. "Bainite in Steels". The Institute of Metals Comunications, 2001. [14] GEMBALOVA, P.; BORUTA, J.; GRYCZ, E.; CMIEL, K.M. "Hot forming parameters research of bearing steel". Arch Civil Mech Eng, p. 721-728, 2007.

[15] SWAHN, H. P.; BECKER, C.; VINGSBO, O. "Martensite Decay During Rolling Contact Fatigue in Ball Bearings". Metallurgical Transactions A, v. 07, n.08. p. 1099 - 1110, agosto de 1976.

[16] CALLISTER, Willian D.; "Ciência e engenharia de materiais: uma introdução”. 7. ed. Rio de Janeiro: LTC, p. 174-176, 2008.

[17] DIETER, George E.; "Mechanical Metallurgy", McGraw-Hill, 3rd Ed., New York, 1981 [18] CHATTOPADHYAY, S.; SELLARS, C.M.; "Kinetics of Pearlite Spheroidization during Static Annealing and during Hot Deformation". Acta Metallurgica, janeiro de 1982. [19] OCHI, T.; KOYASU, Y. ; "Strengthening of Surface Induction Hardened Parts for Automotive Shafts Subject to Torsional Load". SAE Technical Paper Series, 1992.

[20] HERNANDEZ Jr., P.C. et al., "Desenvolvimento de metodologia para avaliação de aços esferoidizados". Tecnol. Metal. Mater. Miner., São Paulo, V.6, n.3, p.158-169, 2010. 
[21] OYAMA, T. et al; "Aplication of the divorced eutectoid transformation to the development of fine-grained, spheroidized structures in ultrahigh carbon steels". Scripta Metallurgica. V. 18, n.8, p. 799 - 894. Agosto de 1984.

[22] KRAUSS, George. "Martensite in Steel: Strength and Structure". Materials Science and Engineering, p. 273 - 275, 1999.

[23] SOUZA, Sérgio Augusto de. "Composição Química dos Aços”. São Paulo: Edgard Blucher, 1989. 